\title{
Estimation of the optimum yield in Yun-Lin area of Taiwan using loss function analysis
}

\author{
Hwa-Sheng Gau ${ }^{\mathrm{a}}$, Chen-Wuing Liu ${ }^{\mathrm{b}, *}$ \\ ${ }^{a}$ Department of Environmental Engineering and Health, Tajen Institute of Technology, Pingtung, Taiwan, ROC \\ ${ }^{\mathrm{b}}$ Department of Agricultural Engineering, National Taiwan University, Taipei, Taiwan, ROC
}

Received 26 June 2001; revised 29 January 2002; accepted 28 February 2002

\begin{abstract}
Safe yield is commonly defined as the largest quantity of water that can be withdrawn without causing any negative effects in the area of interest. When, negative effects are induced by over-pumping, the safe yield must be reinterpreted according to the present conditions. Therefore, the optimum yield, defined as the quantity of water that can be withdrawn from the groundwater aquifer with minimum expected losses, is introduced to balance the economic profit and environmental protection in groundwater management. A decision model based on the loss function concept is presented to estimate the optimum yield from a groundwater basin, which has experienced seawater intrusion and subsidence caused by over-pumping. The model employs loss functions, which account for environmental deterioration and economic profit according to the hydrogeological conditions and pumping rates. The optimum yield from a groundwater basin can thus be obtained by minimizing the expected value of the loss function. The method is applied to a groundwater basin in Yun-Lin, Taiwan. Analysis results indicate that the optimum yield of groundwater in this region is 619 million ton/yr, which is far lower than the current annual groundwater consumption. The method is more conservative than the conventional water balance method and is thus a more effective means of managing water resource conservation. Further environmental damage may be prevented if the loss function method proposed herein for determining the optimum yield can be applied to planning groundwater resources in the future. (C) 2002 Elsevier Science B.V. All rights reserved.
\end{abstract}

Keywords: Optimum yield; Decision analysis; Loss function; Subsidence

\section{Introduction}

The concept of safe yield has long been employed for water balance purposes. Several methods for estimating safe yield, based primarily on the principle of water balance, have been proposed in the literature (Todd, 1959; Mann, 1960; Domenico, 1972; Kazmann, 1972; Freeze and Cherry, 1979; Shen,

\footnotetext{
* Corresponding author. Tel.: +886-2-23626480; fax: +886-223639557.

E-mail address: lcw@gwater.agec.ntu.edu.tw (C.-W. Liu).
}

1986; Tsao and Hsu, 1987). Although various definitions are available in the foregoing literature, safe yield is commonly defined as the largest quantity of water that can be withdrawn without causing any negative effects in the area of interest (Todd, 1959).

When negative effects are induced by over-pumping, the safe yield must be reinterpreted according to the present conditions. As such, optimum yield is defined as the quantity of water that can be withdrawn from the groundwater of an aquifer with minimum expected losses (Domenico, 1972). This definition has become the economic and environmental standard 
in groundwater management. Both negative and positive effects of groundwater pumping must be taken into account while assessing the optimum use of water resources. Negative effects include seawater intrusion, land subsidence, and damage caused by public facilities; positive effects include increases in aquacultural and agricultural production. Simulationoptimization approach has been applied to solve the optimum yield problem for groundwater in a specific area for two decades (Nisai and Mays, 1986; Jones et al., 1987; Jones, 1992; Chan, 1993). However, these techniques cannot easily be applied under field conditions because not only the overall cost of the damage to the environment due to groundwater withdrawal but also the regional hydrogeological characteristics of the aquifers are both required to be provided in detail.

This study adopts a decision model to obtain the optimum yield in Yun-Lin, Taiwan. A probability density function (PDF) of safe yield and loss functions are introduced. The groundwater recharges is mainly from the infiltration of precipitation and can be treated as a random variable with a PDF (Chow et al., 1988). Gau and Liu (2000) show a correlative relation between precipitation and groundwater recharge. Thus, the safe yield PDF is approximated by a rainfall PDF while the loss functions are assigned from the negative and positive effects of water utilization by economic analysis. The optimum yield does not correspond to the peak of the safe yield PDF and is determined by minimizing the expected losses using decision analysis. The optimum yield and the method can serve as references in groundwater management and planning in Yun-Lin, Taiwan.

\section{Decision model}

Decision analysis is effectively and frequently employed in the fields of business and engineering for analyzing systems that have highly uncertain futures (Crouch and Wilson, 1982; Holloway, 1979; Keeney and Raiffa, 1976). Decision analysis solves problems exhibiting great uncertainty and provides reasonable solutions where minimal uncertainty is required. Moreover, the method gives an adequate solution at the least cost. Freeze et al. (1990) conceptually outlined decision analysis in relation to ground- water management. The method has then been applied to designing actions to remedy contaminated groundwater (Massmann et al., 1991), and to the groundwater control system of an open pit mine (Sperling et al., 1992). Freeze et al. (1992) discussed the concept of the data-worth analysis and its use in the development of site investigation strategies.

A feasibility study, addressing safety, is required in any public project. A loss function $L(A, B)$ must initially be constructed to assess the desired action for a given project. This function represents the loss incurred if action $A$ is taken in a natural environment in state $B$. If information regarding $B$ is collected in advance and transformed into a probability distribution function, then techniques such as Baye's criterion (Hogg and Craig, 1989) can select the appropriate decision from the corresponding probability distribution. By applying this criterion, the expected value of the loss function $L(A, B)$, as derived from the corresponding probability distribution of a natural state, can be computed according to Eq. (1) (Hogg and Craig, 1989; Mood et al., 1976).

$R(A)=E[L(A, B)]=\int_{-\infty}^{\infty} L(A, X) P(X) \mathrm{d} X$

where $R(A)$ denotes a risk function, $E[\cdot]$ is the expectation function and $P(X)$ is a PDFof $X$.

If the groundwater is considered as a commodity that may be traded commercially, then utilization of the groundwater can be considered as an index measuring economic loss or gain. Applying economic and environmental concepts, the safe yield is assumed to be $X$ and the corresponding PDF is $P(X)$. An actual yield, $Z$, exceeding the safe yield, $X$, implies that the groundwater is being overused or over-pumped. Overuse of groundwater initially causes the water level to fall, increasing the suction head and consuming excessive electrical power. Various environmental problems may follow; including land subsidence, unsafe embankments, decreased drainage efficiencies, and deteriorated groundwater quality. The net losses caused by over-pumping are expressed in terms of an $L 1$ function. The $L 1$ function depends on the difference between the values of $X$ and $Z$ when $X$ is smaller than $Z$. The value of the $L 1$ function increases as the difference increases. When $Z$ is smaller than $X$ agricultural and aquacultural production does not achieve its maximum possible economic value, the water 


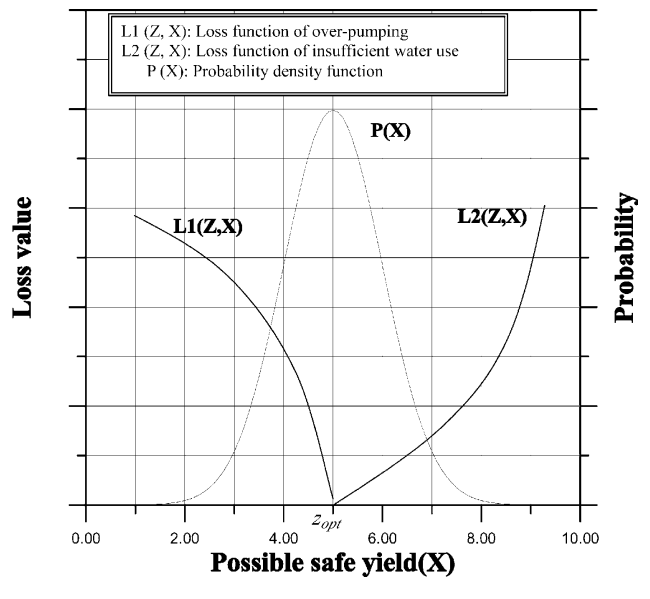

Fig. 1. Relationships among $L 1, L 2$ and $P(X)$.

resources are not sufficiently utilized. Therefore, a loss value is assigned for water resource under-utilization. The losses due to insufficient utilization are represented by an $L 2$ function. The $L 2$ function also increases with the difference between the values of $Z$ and $X$ increases. The yield is optimal, at $Z_{\mathrm{opt}}$, if the actual yield equals the safe yield. For each safe yield, $X$, varying with the PDF $P(X)$, a corresponding loss can be determined from $L 1(Z-X)$ or $L 2(X-Z)$. The total expected loss (TEL) of groundwater in a specific area can then be expressed as

$$
\begin{aligned}
\mathrm{TEL}= & \int_{-\infty}^{\infty} L(X, Z) P(X) \mathrm{d} X \\
= & \int_{-\infty}^{Z} L 1(Z-X) P(X) \mathrm{d} X+\int_{Z}^{+\infty} \\
& \times L 2(X-Z) P(X) \mathrm{d} X
\end{aligned}
$$

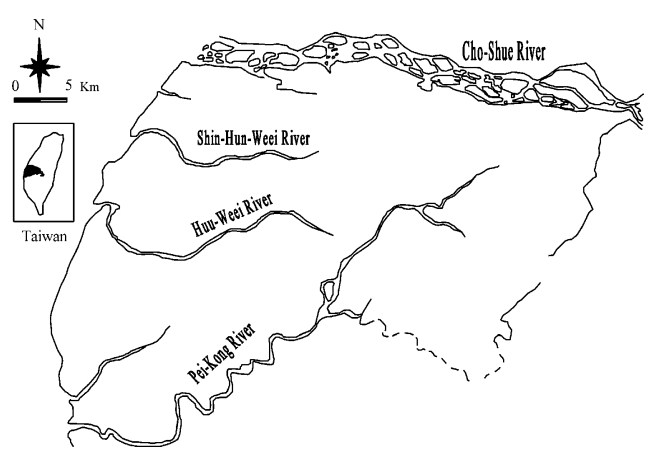

Fig. 2. Geological location of Yun-Lin Basin.
Fig. 1 shows a notion of the loss functions used in the decision analysis. The curves, $L 1(Z, X)$ and $L 2(Z, X)$, describe losses due to over-pumping and under-utilization of groundwater, respectively. The actual yield, $Z$, corresponds to a PDF for safe yield, $P(X)$. The intersection of the $L 1$ and $L 2$ curves, $Z_{\text {opt }}$, denotes where the actual yield is optimal and $P\left(Z_{\text {opt }}\right)$ corresponds to the PDF for the optimum yield. Since $X$ and $Z$ are positive values, TEL then can be stated as,

$$
\begin{aligned}
\mathrm{TEL}= & \int_{0}^{Z} L 1(Z-X) P(X) \mathrm{d} X \\
& +\int_{Z}^{+\infty} L 2(X-Z) P(X) \mathrm{d} X
\end{aligned}
$$

As such, the optimum yield, $Z_{\text {opt }}$, can be obtained by minimizing the TEL function. The estimated $X$ is iteratively substituted into the TEL function; until the correspondent value of $X$ reaches $Z_{\text {opt }}$, to solve the minimization problem. When $Z_{\mathrm{opt}}$ has been obtained, $L 1$ and $L 2$ can be constructed. The solution cannot be solved graphically because $L 1$ and $L 2$ are non-linear functions. The successive quadratic estimation method is employed to solve the determined $Z_{\text {opt }}$ (Reklaities, 1983).

\section{Application}

\subsection{Description of the study area}

The Yun-Lin basin is located in the western part of central Taiwan, as depicted in Fig. 2. The Cho-Shui River and Pei-Kong River are the two major rivers flowing through the basin. The basin extends $48 \mathrm{~km}$ from east to west and $24 \mathrm{~km}$ from north to south and has a total area of approximately $1000 \mathrm{~km}^{2}$. Rainfall is concentrated in the wet season from May to October while the dry season is between November and April. The annual average rainfall and temperature are $1416.8 \mathrm{~mm}$ and $22.6{ }^{\circ} \mathrm{C}$, respectively (Agricultural Engineering Research Center, 1989). The primary conventional source of revenue in the area is agricultural production. However, the average income of farmers in this region is significantly below that of workers in other sectors due to the recent, rapid growth in the industrial sector. Therefore, many farmers have converted their farmlands to aquacultural 


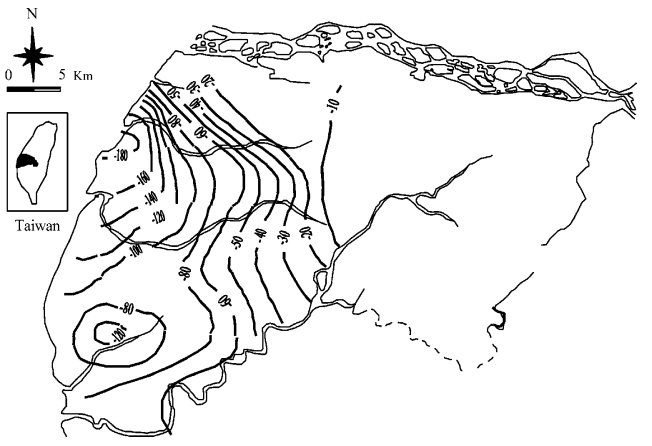

Fig. 3. The contour of cumulative land subsidence from 1985 to 1994 (units in cm, adapted from Du et al., 1996).

operations, demanding large quantities of water, to boost earnings. Many illegal pumping wells have been densely placed along the coastal area. The wells continuously extract groundwater from the aquifer to meet aquacultural demands, and have thus caused serious adverse effects, such as land subsidence, seawater intrusion, and deterioration of the environment, over the past $15 \mathrm{yr}$. Fig. 3 shows contours of representing the cumulative land subsidence from 1985 to 1994 , with values exceeding $180 \mathrm{~cm}$ south of the Shin-Hun-Weei River (Du et al., 1996). Careful placement of wells and management of pumping rates are imperative to minimize these adverse effects.

\subsection{Basic assumptions}

Several assumptions are made in the decision analysis to determine the optimum yield of groundwater resources in Yun-Lin, Taiwan, to simplify the problem:

1. Rainfall is the primary input to the groundwater system. The safe yield correlates with rainfall distribution, and is described by the same probability density distribution. One fifth of the rainfall is assumed effectively to recharge into groundwater aquifers (Liu and Zhang, 1993).

2. The loss function $L 2$ is constructed according to the relationship between water usage and income loss, when the water is not sufficiently supplied to aquaculture. Agricultural water is primarily supplied by surface water from the Cho-Shui River. The underutilization of groundwater does not influence agricultural production.

3. The loss function $L 1$ is approximated by the relationship between the water usage and the repair cost, due to the over-extraction groundwater, which destroys roads and damages embankments.

\subsection{Rainfall data analysis}

The basic precipitation data were gathered mainly from 21 rainfall-monitoring stations between 1960 and 1985 (C.W.B., 1960-1985). Annual average rainfall was computed by the Thiessen polygon method. The rainfall PDFs were constructed according to four statistical models including normal, lognormal, gamma, and exponential distributions. Table 1 lists the computed results. The gamma distribution model is defined as,

$f(x)=\frac{1}{\beta \Gamma(\alpha)}\left(\frac{x}{\beta}\right)^{\alpha-1} \mathrm{e}^{-(x / \beta)}$

where $\Gamma($ ) is gamma function, and $\alpha$ and $\beta$ are shape and scale parameters, respectively. The gamma distribution model with shape and scale parameters of 23.08 and 61.73 , respectively, is the most significant statistically and is thus adopted as the PDF to describe

Table 1

Statistic tests of rainfall probability distribution

\begin{tabular}{llll}
\hline Model & Parameter & Chi-square test & Significant \\
\hline Normal & $\begin{array}{l}\text { Mean: } 1416.8 \\
\text { Standard deviation: 293.65 }\end{array}$ & 16.905 & 0.079 \\
Log normal & $\begin{array}{l}\text { Mean: } 1419.2 \\
\text { Standard deviation: 311.46 }\end{array}$ & 2.578 & 0.108 \\
Gamma & $\begin{array}{l}\text { Shape: } 23.08 \\
\text { Scale: } 61.73 \\
\text { Exponential }\end{array}$ & 2.506 & 0.113 \\
\hline
\end{tabular}


Table 2

The quantity, price and water use to the estimation of fish production value

\begin{tabular}{|c|c|c|c|c|c|c|c|c|c|c|}
\hline Fish species & & Milk fish & Tilapia & Eel & Shrimp & Sea perch & Clam & Cookle & $\begin{array}{l}\text { Total value in } \\
10^{6} \mathrm{NT} \text { dollars }\end{array}$ & $\begin{array}{l}\text { Total water } \\
\text { consumption }(\mathrm{cm} / \mathrm{yr})\end{array}$ \\
\hline $\begin{array}{l}\text { Water used } \\
\text { (tons/ton/yr) }\end{array}$ & & 41000 & 31000 & 532000 & 133000 & 88000 & 37000 & 59000 & & \\
\hline \multirow[t]{2}{*}{1982} & Quantity (ton) & 1441 & 6121 & 5673 & 1540 & 4437 & 3992 & 3243 & 263.5 & 420.12 \\
\hline & Value $\left(10^{6}\right.$ NT dollars $)$ & 7.2 & 24.5 & 147.5 & 15.3 & 19.2 & 31.9 & 17.8 & & \\
\hline \multirow[t]{2}{*}{1983} & Quantity (ton) & 1536 & 6609 & 4381 & 2000 & 509 & 5337 & 3146 & 251.6 & 325.34 \\
\hline & Value ( $10^{6}$ NT dollars $)$ & 9.1 & 26.8 & 111.8 & 41.5 & 2.5 & 42.7 & 17.3 & & \\
\hline 1984 & Value $\left(10^{6}\right.$ NT dollars $)$ & 7.6 & 23.9 & 140.1 & 43.8 & 2.1 & 44.3 & - & & \\
\hline \multirow[t]{2}{*}{1985} & Quantity (ton) & 1571 & 5872 & 5520 & 2504 & 3927 & 6900 & 3126 & 242.1 & 386.71 \\
\hline & Value $\left(10^{6}\right.$ NT dollars $)$ & 8.3 & 23.0 & 134.1 & 60.0 & 16.7 & 48.8 & 12.3 & & \\
\hline \multirow[t]{2}{*}{1986} & Quantity (ton) & 1411 & 5197 & 4566 & 3423 & 3553 & 6202 & 2932 & 192.12 & 339.84 \\
\hline & Value ( $10^{6}$ NT dollars) & 11.4 & 20.3 & 110.1 & 37.1 & 12.4 & 44.3 & 11.4 & & \\
\hline \multirow[t]{2}{*}{1987} & Quantity (ton) & 1890 & 4940 & 3908 & 3283 & 3175 & 3933 & 2754 & 174.8 & 302.57 \\
\hline & Value $\left(10^{6}\right.$ NT dollars $)$ & 13.5 & 14.9 & 105.5 & 29.7 & 11.2 & 8.8 & 12.1 & & \\
\hline \multirow[t]{2}{*}{1988} & Quantity (ton) & 176 & 5869 & 9830 & 1013 & 7175 & 8997 & 1325 & 379.8 & 617.46 \\
\hline & Value $\left(10^{6}\right.$ NT dollars $)$ & 1.2 & 19.4 & 26.2 & 12.7 & 29.8 & 494.8 & 5.2 & & \\
\hline 1989 & Value ( $10^{6}$ NT dollars) & 0.5 & 21.7 & 215.5 & 11.4 & 28.7 & 43.6 & 14.9 & & \\
\hline \multirow[t]{2}{*}{1990} & Quantity (ton) & 450 & 5500 & 13224 & 254 & 4828 & 6660 & 5516 & 459.2 & 825.46 \\
\hline & Value $\left(10^{6}\right.$ NT dollars $)$ & 1.8 & 23.1 & 330.6 & 7.0 & 26.4 & 40.0 & 30.3 & & \\
\hline
\end{tabular}




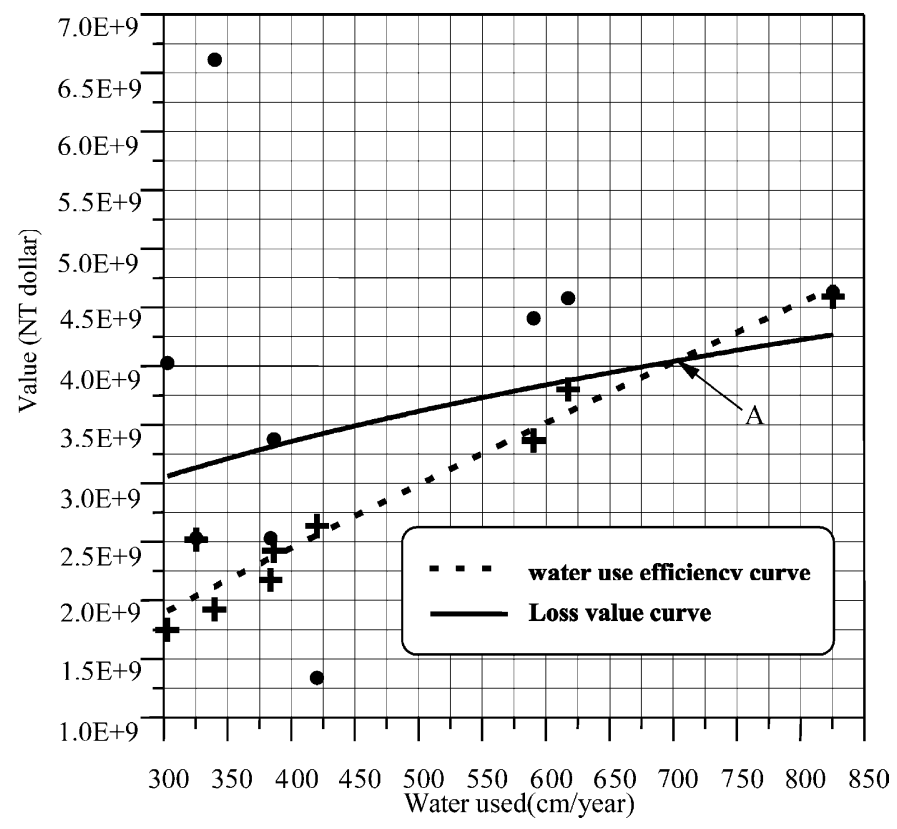

Fig. 4. Loss value curve and water use efficiency curve.

Loss from overdraft of water; + water utilization profit.

the probability distributions of the rainfall. The aquifer is formed primarily from alluvial deposits in Yun-Lin, and rainfall may recharge directly into the unconfined sandy aquifer. Consequently, the safe yield PDF is approximated by the rainfall PDF. The effective groundwater recharge coefficient can be estimated from the correlation between long-term precipitation and the variation of the groundwater table. Only $20 \%$ of the rainfall is assumed to be effectively recharged into the groundwater aquifer (Liu and Zhang, 1993). Accordingly, the safe yield is one fifth of the rainfall and the gamma distribution model with shape and scale parameters of 4.616 and 0.9232 is statistically fitted to the probability distribution of the safe yield.

\subsection{Estimation of aquacultural water consumption}

Economic activity in Yun-Lin relies heavily on aquaculture. Milkfish, tilapia, eel, shrimp, sea perch, clam and cockle are raised. The volume of water required for fish farming of various species depends on the number and type of fish farmed, the aquacultural technology applied, and the structure of the fishponds. The water consumption required for different fish varies: 41,000 tons/ton/yr for milkfish,
31,000 tons/ton/yr for tilapia, 532,000 tons/ton/yr for eel, 133,000 tons/ton/yr for shrimp, 88,000 tons/ton/ yr for sea perch, 37,000 tons/ton/yr for cockle (See the Annual Reports of Agriculture in Taiwan, 19821990). The total value of fish production and the total consumption of water can be computed from the amount of fish produced from 1982 to 1990 and their market values (Table 2).

\subsection{Setup of loss functions}

Fig. 4 displays the water use efficiency curve and the loss value curve. The abscissa denotes the amount of water used annually, while the ordinate is the loss or profit. For a given volume of water, if the profit is smaller than the loss, the water is over-extracted. If these two curves are extended, they will intersect at some point (point $A$ in this case). However, the intersection does not represent reality because the environment has seriously deteriorated, as the profit and the loss have not been distributed to the same people: the profit is enjoyed by aquacultural business and the loss is imposed on local residents and the local government. This problem can be resolved by using decision 
Table 3

An accumulated land subsidence from 1982 to 1990 and a estimated cost for the repair of road and bridge destruction

\begin{tabular}{lllcl}
\hline Year & $\begin{array}{l}\text { Accumulated land } \\
\text { subsidence } \\
(\mathrm{cm})\end{array}$ & $\begin{array}{l}\text { Repair cost for } \\
\text { provincial road } \\
\left(10^{6} \text { NT dollars }\right)\end{array}$ & $\begin{array}{l}\text { Repair cost for } \\
\text { prefectural road } \\
\left(10^{6} \text { NT dollars }\right)\end{array}$ & $\begin{array}{l}\text { Repair cost } \\
\text { for bridge } \\
\left(10^{6} \text { NT dollars }\right)\end{array}$ \\
\hline 1982 & 9.71 & 432.2 & 86.5 & 649.4 \\
1983 & 17.48 & 777.9 & 155.7 & 649.4 \\
1984 & 26.22 & 1166.9 & 233.6 & 649.4 \\
1985 & 34.96 & 1555.9 & 311.4 & 649.4 \\
1986 & 42.73 & 1901.6 & 380.6 & 649.4 \\
1987 & 49.53 & 2204.1 & 441.2 & 649.4 \\
1988 & 64.10 & 2670.0 & 534.5 & 649.4 \\
1989 & 77.70 & 2670.0 & 534.5 & 649.4 \\
1990 & 97.12 & 2670.0 & 534.5 & \\
\hline
\end{tabular}

analysis to obtain a compromise solution that balances the probabilities of the profit and the loss functions.

\subsubsection{L2 function}

The relationship between the value of fish and water utilization is constructed from the results in Table 2.
The cross symbols in Fig. 4 indicate the annual value of the fish produced against the annual water used from 1982 to 1990 . Four types of curves including power, linear, logarithmic and exponential were used to achieve the best fit by regression analysis. The results suggest that the power curve gives the

Table 4

Loss from crop (in $10^{6}$ NT dollars)

\begin{tabular}{|c|c|c|c|c|c|c|c|c|c|}
\hline \multirow[t]{2}{*}{ Species } & \multicolumn{9}{|l|}{ Year } \\
\hline & 1982 & 1983 & 1984 & 1985 & 1986 & 1987 & 1988 & 1989 & 1990 \\
\hline Rice & 6.8 & 8.6 & 53.9 & 137.7 & 699.7 & 169.1 & 22.9 & 74.6 & 48.6 \\
\hline Sweet potatoes & & 8.4 & 0.5 & 10.0 & 177.1 & 4.5 & 2.5 & 1.2 & 8.0 \\
\hline Maize & 1.1 & 10.4 & & 15.1 & 127.1 & 71.8 & 11.8 & 63.8 & 33.4 \\
\hline Sorghum & & 1.8 & 0.3 & 8.3 & 14.9 & & 2.7 & 2.2 & 11.2 \\
\hline Sugar cane (fresh) & & 2.2 & & 3.1 & 170.6 & 5.6 & 1.4 & 75.9 & 29.3 \\
\hline Soybean & & 0.1 & & 0.7 & 22.4 & 2.3 & 7.9 & 2.1 & 4.7 \\
\hline Other bean & 3 & & & & & & & & \\
\hline Sugar cane & & & 1.4 & 14.4 & 15.6 & & 7.1 & 62.4 & \\
\hline Peanuts & 25.2 & 142716 & 81638 & 142035 & 448140 & 86.7 & 39.8 & 45.4 & 82.1 \\
\hline Special crops & 8.1 & 0.3 & & & 23.2 & 7.8 & & & \\
\hline Asparagus & 4.2 & 72.7 & 58.2 & 32.1 & 205.2 & 58.9 & 65.2 & & \\
\hline Watermelons & 42.9 & 178.5 & 94.6 & 158.1 & 39.8 & 13.8 & 55.7 & 0.8 & 258.4 \\
\hline Seed watermelons & & & & 150.6 & 151.1 & 68.4 & 45.2 & & \\
\hline Nuskmelons & & & & 53.2 & 268.5 & 84.6 & 19.0 & 32.8 & 73.3 \\
\hline Other vegetable & 78.2 & 521.2 & 189.7 & 132.8 & 1179.0 & 154.2 & 43.0 & 91.5 & 225.4 \\
\hline Potatoes & & 7.6 & & & & & & & \\
\hline Other fruit & & 106.1 & & & 16.4 & & 3.9 & 1.6 & \\
\hline Bamboo shoots & & & & & 272.3 & & 1.5 & 17.2 & \\
\hline Bananas & & & & & 27.4 & & & 11.0 & \\
\hline Linchengs & & & & & 344.7 & & & 3.6 & \\
\hline Ornamental plants & & & & & 1.4 & & 0.7 & 0.2 & 1.2 \\
\hline Papayas & & & & & & & & 8.1 & 21.6 \\
\hline Guavas & & & & & & & & 0.5 & \\
\hline Total & 169.5 & 947.2 & 479.9 & 858.2 & 3682.1 & 727.9 & 724.1 & 552.8 & 774.5 \\
\hline
\end{tabular}


best fit as shown by the dashed line in Fig. 4 with a regression equation given by,

$Y=1.1775 \times 10^{7} \times W^{0.8908}$

where $Y$ is the total value attributed to fish production in New Taiwan (NT) dollars and $W$ is the annual water consumption in $\mathrm{cm} / \mathrm{yr}$.

The $L 2$ loss function is defined as the losses attributable to insufficient water use. If an actual yield $Z$ is used for aquaculture in a given year. The profit can be computed from Eq. (5) by replacing $W$ with $Z$. If the water is exploited sufficiently and becomes a safe yield $X$, the profit can still be directly computed from Eq. (5) by replacing $W$ with $X$. If the $Z$ is less than the $X$, the net loss from insufficient water use for aquaculture in the year of interest is simply described by the difference between these two. Thus, the net loss of the $L 2$ function can be expressed as

$L 2(X-Z)=1.1775 \times 10^{7} \times\left(X^{0.8908}-Z^{0.8908}\right)$,

$(Z<X)$

\subsubsection{L1 function}

The losses considered herein include the destruction of embankments and roads caused by land subsidence, and economic and social losses caused by flooding. Data for affected areas were obtained mainly from the 1989 report of the Agricultural Engineering Research Center.

The surface of a road is assumed to be $60 \mathrm{~cm}$ thick. If land subsidence exceeds $60 \mathrm{~cm}$, the road structure cracks and must be rebuilt. If the subsidence is less than $60 \mathrm{~cm}$, the road requires only partial resurfacing. The cost of resurfacing is assumed proportional to the amount of subsidence. If subsidence occurs around a bridge, the bridge becomes unsafe and must be replaced. According to land subsidence surveys, the areas of provincial roads, prefectural roads, and bridges destroyed were $667,500,255,500$ and $43,290 \mathrm{~m}^{2}$, respectively. The repair costs for provincial roads, prefectural roads, and bridges were 4000, 260 and $15,000 \mathrm{NT} \$ / \mathrm{m}^{2}$, respectively. Table 3 gives estimates of the total repair costs.

The destruction of embankments by land subsidence means that floods can no longer be controlled. Flooding due to the river's overflowing in wet seasons, causes water to accumulate and crop production to fall. Accordingly, the losses considered herein are crop losses caused by flooding following the destruction of embankments. The lost value due to damaged crops is obtained mainly from Taiwan's Annual Agriculture Reports from 1982 to 1990. Table 4 lists the loss value of different crops. The solid circles in Fig. 4 show the relationship between the total loss according to the earlier estimate, and the amount of water used. The total loss $(Y)$ can be expressed as a function of water usage $(W)$ by curve-fitting and is shown by the solid line in Fig. 4:

$Y=4.589 \times 10^{8} W^{0.332}$

The loss exists if the actual yield $(Z)$ exceeds the safe yield $(X)$. Thus, the loss caused by over-extraction of groundwater becomes,

$$
L 1(Z-X)=4.589 \times 10^{8}(Z-X)^{0.332}, \quad(Z>X)
$$

The loss functions are represented in general form as to describe the process of solving for optimum $Z$ :

$L 1(Z-X)=a_{1}(Z-X)^{b_{1}}$

$L 2(X-Z)=a_{2} X^{b_{2}}-a_{2} Z^{b_{2}}$

Substituting Eqs. (9) and (10) into Eq. (3), and differentiating TEL with respect to $Z$, using Leibnitz's rule, and then setting $d(T E L) / d z=0$, the following is obtained,

$$
\begin{aligned}
\frac{\mathrm{d}(\mathrm{TEL})}{\mathrm{d} Z}= & a_{1} b_{1} \int_{0}^{Z}(Z-X)^{b_{1}-1} P(X) \mathrm{d} X \\
& -a_{2} b_{2} Z^{b_{2}-1} \int_{Z}^{\infty} P(X) \mathrm{d} X \\
= & 0
\end{aligned}
$$

The extreme value of $Z$ is found by solving Eq. (11) using the successive quadratic estimation method (Reklaities, 1983). The necessary condition for $Z$ to be a minimum of TEL is that the second derivative of TEL is greater than zero. Differentiating Eq. (11) 


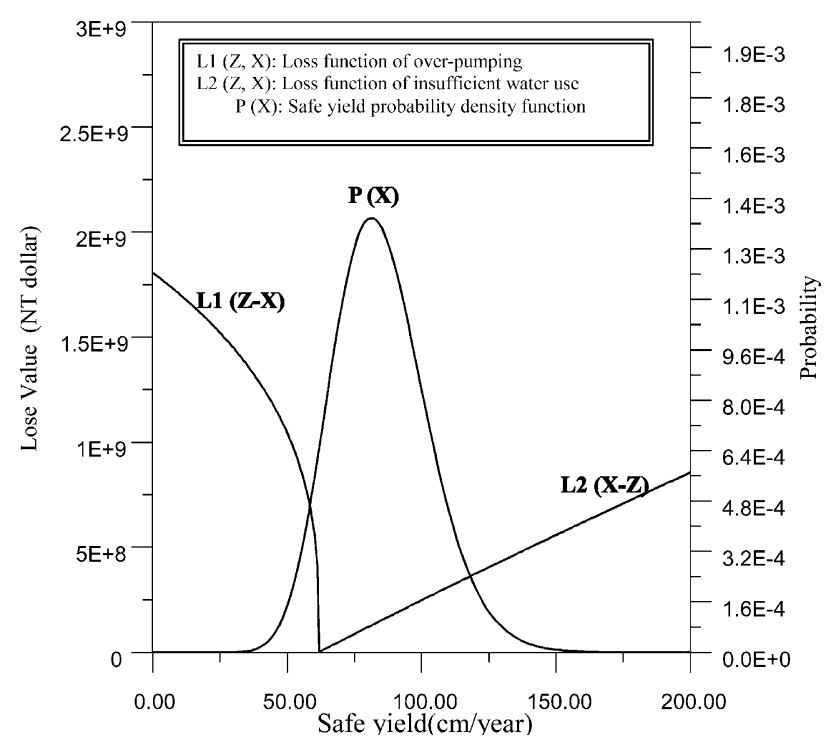

Fig. 5. Optimum yield for Yun-Lin area.

again,

$$
\begin{aligned}
\frac{\mathrm{d}^{2}(\mathrm{TEL})}{\mathrm{d} Z^{2}}= & {\left[a_{1} b_{1}\left(b_{1}-1\right)\right] \int_{0}^{Z}(Z-X)^{b_{1}-2} P(X) \mathrm{d} X } \\
& -\left[a_{2} b_{2}\left(b_{2}-1\right) Z^{b_{2}-2}\right] \int_{Z}^{+\infty} P(X) \mathrm{d} X \\
& +\left[a_{2} b_{2} Z^{b_{2}-1}\right] P(Z) \\
> & 0
\end{aligned}
$$

substituting the regression coefficients $a_{1}, b_{1}, a_{2}$ and $b_{2}$ given in Eqs. (6) and (8), and the rainfall PDF of Eq. (4) into Eq. (12), respectively, we then compute the integral values of $\mathrm{d}^{2}(\mathrm{TEL}) / \mathrm{d} \mathrm{Z}^{2}$ by the numerical software IMSL (International Mathematics and Statistics Library, Inc., 1987). The results show that $\mathrm{d}^{2}(\mathrm{TEL}) / \mathrm{d} Z^{2}$ is always greater than zero as the value of $Z$ ranges from zero to infinity. Therefore, the solution of Eq. (11) yields the $Z_{\mathrm{opt}}$ is a minimum value of TEL.

\section{Results and discussion}

Decision analysis is performed to estimate the optimal yield using the $L 1$ and $L 2$ functions and the PDF of the safe yield. The latter is approxi- mated by the rainfall PDF. The optimum yield is determined by $\mathrm{d}(\mathrm{TEL}) / \mathrm{d} Z=0$. Fig. 5 presents the results. The optimum yield is $61.9 \mathrm{~cm} / \mathrm{yr}$ which is corresponding to the intersect of the $L 1$ and $L 2$ curves on $x$-axis. Multiplying this value by $1000 \mathrm{~km}^{2}$, the approximate area of Yun-Lin, gives an optimum yield of 619 million metric tons/yr. This finding is compared with the safe yield of 770 million metric tons/yr estimated by Tsao and Hsu (1987) using a water balance method in the Yun-Lin basin. Their value is 150 million metric tons higher than that obtained in this study. The actual water consumption from 1982 to 1990 in this area $(300 \mathrm{~cm} / \mathrm{yr}$ or higher, as shown in Table 2) is significantly higher than the optimum yield found in this study (equal to $61.9 \mathrm{~cm} / \mathrm{yr}$ ).

This finding also agrees with the observation of severe land subsidence in the area, thereby supporting the view that over-pumping of groundwater by aquaculture induces land subsidence in Yun-Lin, Taiwan.

Fig. 5 shows the relationship between the loss functions and the safe yield probability distribution. In this decision analysis model, the optimum yield is mainly controlled by the loss functions and the probability distribution. Nevertheless, the probability distribution of the safe yield, approximated by the rainfall probability distribution, in an area is a natural inherent 
function so that the optimum yield can only be increased by adjusting the loss functions. Fig. 5 shows that the loss decreases by decreasing the slope of the $L 2$ function. In other words, the optimum yield is increased by reducing the loss from insufficient water usage. This concept can be elucidated by considering raising eels and shrimps with the highest unit profit and noting the proportional increases in water demand (see Table 2). The slope of the profit curve will increase so that the slope of the $L 2$ function is accordingly reduced if the locations of eel and shrimp ponds are properly placed to avoid environmental damage, such as land subsidence. Such placement correspondingly increases the optimum yield.

Results obtained from decision analysis and the water balance method must be interpreted separately. In the water balance method, the safe yield is the difference between the volumes of water recharge and extraction, and is the maximum volume of water that can be utilized without considering environmental factors. The volume of water obtained from the water balance method exceeds that obtained from decision analysis since the former does not consider environmental factors. The water balance method is only appropriate for an area that has previously undergone no environmental damage. Applying the water balance method requires detailed hydrological and hydrogeological data, including the rate of river flow and the amount of groundwater supplied, to be collected in advance. However, these data are sometimes difficult to measure, resulting in high uncertainty and low reliability.

The decision analysis method is more conservative and is appropriate for an area that has experienced environmental damage. Decision analysis requires only data related to statistically valid loss functions. Collecting such data is relatively simple.

This study did not include some losses, such as the cost of replacing soil, the cost of repairing the damage to pumping wells, and the cost of improving the health and safety of the farming population. Therefore, the actual optimum yield may be lower than 619 million tons. Moreover, a statistical analysis of existing data cannot easily determine accurately the actual loss from over-extraction. Consequently, the results may exhibit a high variance with a large uncertainty.
The monthly average optimum yield could be calculated if monthly average data were available. Such results would be more accurate than the yearly average optimum yield determined in the present study.

The probability distribution of the safe yield must be pre-estimated for decision analysis. This study, based on earlier work (Liu and Zhang, 1993), assumed that $20 \%$ of rainfall recharges into the groundwater aquifer. However, the groundwater recharge may be different from this value for different hydrogeological setting of interest. The difference could lead to a significant difference in the determined optimum yield.

\section{Conclusions and suggestions}

Decision analysis and loss functions are introduced to estimate the optimum yield from a groundwater aquifer. Two loss functions, $L 1$ and $L 2$, are constructed. The $L 1$ function represents the loss due to environmental deterioration caused by overextracting of groundwater. The $L 2$ function represents the loss of economic profit caused by under-utilization of groundwater. An optimum yield for the groundwater aquifer can be determined by minimizing TEL function. The technique is adopted to estimate the optimum yield in Yun-Lin, Taiwan. The computed optimum yield is 619 million tons per year, which is much less than the actual amount extracted and less than the value computed by the water balance method. The optimum yield may have been even lower if more data were available to calculate the loss functions. The low value of the optimum yield indicates that the groundwater resource in Yun-Lin, Taiwan suffers from severe over-extraction. Over-extraction has caused environmental deterioration, seawater intrusion, land subsidence, embankment failure, and road destruction. The loss function decision analysis approach adequately determines the optimum yield in Yun-Lin, Taiwan. It is more conservative and efficient than the conventional water balance method and more thoroughly considers environmental factors.

\section{Acknowledgements}

The authors would like to acknowledge the 
National Science Council of the Republic of China for financially supporting this research under Contract No. NSC 89-2625-Z-002-016. We thank two anonymous reviewers and the editor (M. Sophocleous), who assisted in many key refinements.

\section{References}

Agricultural Engineering Research Center, 1989. Application of mathematic model of groundwater resources in Cho-Shue Alluvial plain. AERC-89-RR-15, Taiwan.

Annual Reports of Agriculture in Taiwan, 1982-1990. Taiwan Government, Republic of China.

Chan, N., 1993. Robustness of the multiple realization method for stochastic hydraulic aquifer management. Water Resour. Res. 29 (9), 3159-3167.

Chow, V.T., David, R.M., Mays, L.W., 1988. Applied Hydrology. McGraw-Hill, Singapore 572pp.

Crouch, E.A.C., Wilson, R., 1982. Risk/Benefit Analysis. Ballinger, Boston, MA 218pp.

C.W.B., 1960-1985. Year Book of Climate, Central Weather Bureau, Taiwan Government, Republic of China.

Domenico, P.A., 1972. Concepts and Models in Groundwater Hydrology. McGraw-Hill, New York 405pp.

Du, F.L., Yang, S.O., Leuo, J.S., Liang, M.L., 1996. The investigation and prediction of land subsidence on Yun-Lin area. Conference on Ground water and Hydrogeology of Choushui Alluvial Plain, Taiwanm. pp. 297-315.

Freeze, R.A., Cherry, J.A., 1979. Groundwater. Prentice-Hall, Englewood Cliffs 604pp.

Freeze, R.A., Massmann, J., Smith, L., Sperling, T., James, B., 1990. Hydrogeological decision analysis: 1. Framework. Ground Water 28 (5), 738-766.

Freeze, R.A., James, B., Massmann, J., Sperling, T., Smith, L., 1992. Hydrogeological decision analysis: 4. The concept of data worth and its use in the development of site investigation strategies. Ground Water 30 (4), 574-588.

Gau, H.S., Liu, C.W., 2000. Estimation of the effective precipitation recharge coefficient in an unconfined aquifer using stochastic analysis. Hydrol. Process. 14, 811-830.
Holloway, C.A., 1979. Decision Making under Uncertainty. Prentice-Hall, Englewood Cliffs 522pp.

Hogg, R.V., Craig, A.T., 1989. Introduction to Mathematical Statistics. . Fourth ed.Macmillan, New York 438pp.

International Mathematics and Statistics Library, Inc.,, 1987. IMSL User's Manual. IMSL, Inc, Houston, TX.

Jones, L., 1992. Adaptive control of groundwater hydraulics. ASCE J. Water Resour. Plan. Mgmt 118 (1), 1-17.

Jones, L., Willis, R., Yeh, W.W-G., 1987. Optimal control of nolinear groundwater hydraulics using differential dynamic programming. Water Resour. Res. 23 (11), 2097-2106.

Kazmann, R.G., 1972. Modem Hydrology. Harper and Row, New York 365pp.

Keeney, R.L., Raiffa, H., 1976. Decision with Multiple Objectives. Wiley, New York 569pp.

Liu, Y., Zhang, C., 1993. A comparative study of calculation methods for recharge of rainfall seepage to ground water in plain area. Ground Water 31 (1), 12-18.

Mann, Jr., J. F., 1960. Safe yield change in groundwater basin. International Geological Congress. XXI Session, Part XX.

Massmann, J., Freeze, R.A., Smith, L., Sperling, T., James, B., 1991. Hydrogeological decision analysis: 2. Applications to ground-water contamination. Ground Water 29 (4), 536-538.

Mood, A.M., Graybill, F.A., Boes, D.C., 1976. Introduction to the Theory of Statistics. McGraw-Hill, New York 564pp.

Nisai, W., Mays, L.W., 1986. Optimal management of large-scale aquifer methodology and application. Water Resour. Res. 22 (4), 447-466.

Reklaities, G.V., 1983. Engineering Optimization. Wiley, New York 684pp.

Shen, S.B., 1986. Investigation the safe yield of ground water in Chang-Hua area. J. Chin. Agric. Engng 32 (4), 65-84.

Sperling, T., Freeze, R.A., Massmann, J., Smith, L., James, B., 1992. Hydrogeological decision analysis: 3. Applications to design of a groundwater control system at an open pit mine. Ground Water 30 (3), 376-389.

Todd, D.K., 1959. Groundwater Hydrology. Wiley, New York 336pp.

Tsao, Y.S., Hsu, R.T., 1987. Application of linear model on safe yield of groundwater. J. Chin. Agric. Engng 33 (2), 28-35. 